\title{
Blended learning and postgraduate skills: rethinking MA History
}

Matthew McCormack, University of Northampton

Natalie Hanley-Smith, University of Northampton

\begin{abstract}
This study focuses on the implications of blended learning for taught postgraduate education. It takes as its focus the pilot year of the MA History at the University of Northampton, which had been redesigned to blend online and face-to-face delivery. By employing a student researcher to canvass students' views, the project evaluates the implications of the delivery mode for the specific skills associated with the discipline of History. As well as evaluating this particular programme, the project uses it as a case study to develop a transferable framework for blended learning. The article argues that both online and classroom delivery can develop the key skills associated with postgraduate study in History, but in significantly different ways, so combining them in an effective blend can offer a pedagogical enhancement.
\end{abstract}

Keywords: Blended learning; e-learning; postgraduate

\section{Introduction}

Blended learning is much discussed in the Higher Education sector at present. In general terms, blended learning combines online and face-to-face methods, seeking to maximise their respective advantages and minimising their drawbacks (Osguthorpe \& Graham, 2003, p.227). Although this mode of delivery has many clear pedagogical benefits, it is often advocated for its practical benefits in terms of cost, convenience and efficiencies with large cohorts (Campbell \& Kimball, 2010; Garrison \& Kanuka, 2004, p.100). Furthermore, much of the critical literature focuses on the undergraduate experience: the pedagogical implications of this mode of delivery are potentially very different for courses that operate at a more advanced level, with distinctive skills requirements (Sharpe et al., 2006). Although distance and online learning are important features of the postgraduate landscape, published studies of blended learning often relate to large professional development courses (McConnell, 2005; Smyth et al., 2012). This study therefore explores the implications of blended learning for taught postgraduate courses in the humanities, and for the much smaller cohorts that typically take them. In particular, it focuses the redesign of the MA History at the University of Northampton, in order to explore whether a blended delivery mode can enhance the acquisition of the specific skills associated with postgraduate study in History.

\section{Literature Review}

There is now a large critical literature on blended learning in HE. Surveys of this literature underline the huge variety of potential 'blends', and the different levels at which these can operate (McGee \& Reis, 2012). Sharpe et al. identify three main ways in which the term is 
currently used: firstly, the provision of supplementary resources for traditional courses; secondly, the use of technology for transformative course redesign; and thirdly, where students are encouraged to take 'a holistic view of the interaction of technology and their learning' (2006, p.2). The vast majority of courses taught in HE now fit the first definition. All modules at the University of Northampton have an accompanying module site on the Blackboard Virtual Learning Environment (VLE). Forms of assessment and feedback are already being done online. Students use online spaces to talk to tutors and each other, and increasingly access learning resources in electronic rather than physical forms. Much of this has happened incrementally: the VLE began life as a notice board and a document store, but increasingly took on more interactive features, to the extent that much learning and teaching is now taking place through the VLE. As with anything that happens incrementally, however, it is not the same thing as taking a step back and consciously planning that something should happen in a particular way, for a particular end. Indeed, Gulc argues that a 'holistic approach has to be taken to the development of blended learning programmes if they are to be successful' (2006, p.19). The various elements have to be viewed together, and the blend has to align with the aims of the programme.

Advocates of blended learning emphasise its wide range of benefits. As Gulc notes, learners don't just like one way to learn, so we should provide as many ways for them to receive their educational programme as possible' (2006, p.19). This allows different students to play to their different strengths. Learning experiences can therefore be more individualised and - if set up carefully - can foster independent learning (McGee \& Reis, 2012, p.16). At the same time, online environments also offer opportunities for collaborative learning, where individuals learn from other learners as well as tutors (Dale, 2006, p. 12). Garrison and Kanuka argue that blended learning can facilitate a community of inquiry: this provides the conditions for 'free and open dialogue, critical debate, negotiation and agreement - the hallmark of higher education'. Faceto-face sessions can build community, whereas 'discussing a complex issue that requires reflection may be better accomplished through an asynchronous Internet discussion forum' (2004, p.97).

The provision for both synchronous and asynchronous communication is a key pedagogical benefit of blended learning programmes. The former include face-to-face teaching and also online discussions that take place at a particular time. The latter is a particular feature of online learning, since an online seminar conducted through a discussion board, say, can take place over a matter of hours, days or weeks. McGee and Reis caution that studies of blended learning place much more emphasis on asynchronous than synchronous activities, more on the 'online' than the 'class' elements, and more on the technology than the activities themselves (2012, p.14). There is an educational value to synchronous, face-to-face communication, where discussion is happening in the moment and participants are responding to a point that has just been made. On the other hand, this does preclude contributions that participants think of after the conversation has moved on. The French have a phrase for it: l'esprit d'escalier, or the wit of the staircase - the frustration of thinking of the perfect retort after the moment has passed. As well as enabling responses that are out of sync, online discussions allow time for participants to make considered responses and to research their contributions, and allow several 'threads' of a discussion to continue simultaneously. As Holden and Poole (2010) note, this is useful when students are handling complex material and is therefore particularly relevant to postgraduate education. 
Most studies of blended learning in HE are generic in terms of discipline. In order to focus on skills development, however, it is useful to be more specific since different disciplines involve different skill sets. The UK Quality Assurance Agency's subject benchmark for History sets out seven 'skills and qualities of mind' associated with the historian:

1. The ability to understand how people have existed, acted and thought in the always differing context of the past...

2. The ability to read and analyse texts and other primary sources, both critically and empathetically, while addressing questions of genre, content, perspective and purpose...

3. The appreciation of the complexity and diversity of situations, events and past mentalities...

4. The understanding of the problems inherent in the historical record itself...

5. Basic critical skills: a recognition that ... historians operate by rules of evidence which, though themselves subject to critical evaluation, are also a component of intellectual integrity and maturity.

6. Intellectual independence [incorporating] the skills of the researcher, namely the ability to set tasks and solve problems...

7. Marshalling an argument: in written and oral form, drawing on and presenting all of the above skills.

(QAA, 2008a, p.4-5)

Whereas some of these skills are common to other disciplines - such as numbers six and seven most of them, and certainly in this combination, are unique to History. The subject benchmarks refer to undergraduate degrees, but as the QAA's descriptors for HE qualifications make clear, these same skills are manifested at a higher level in Master's degrees, with a greater emphasis on originality, independence and methodological reflexivity (QAA, 2008b, p.18-21). A change to the form of a course is likely to change its pedagogical content, so this project focuses on the impact of a shift towards blended learning delivery upon these key History skills.

There are a handful of existing case studies that explore blended learning within the discipline of History, generally focusing on a particular module or course. They focus on the use of a particular online activity within a blend, such as discussion boards (Navickas, 2010), online seminars (Timmins, 2004) or weblogs (Dawson et al., 2007), rather than the structure of the blend itself. Some studies advocate the use of automated online tasks such as quizzes (Whitelaw, 2006); while undoubtedly efficient when dealing with large numbers of students, these purely test knowledge, which may have a limited application in undergraduate teaching but has no place in advanced postgraduate work. Although most of these studies concern undergraduate programmes, Holden and Poole carried out a study of three modules on their History MA at the University of the West of England that incorporated discussion boards. This study evaluated the advantages and disadvantages of discussion boards for students and staff alike, and in particular focused on the impact of assessing student participation. Although they felt that there were 'too many variables between modules to draw any clear conclusions' (2010, p.16), they nevertheless demonstrated the value of thinking about the specific implications of blended learning for parttimers, postgraduates and historians. 


\section{Context}

The specific focus of this study is the MA History at the University of Northampton in the academic year 2013-14. The History division had long had a taught Masters course that ran in the evening on a part-time basis, but in recent years it had struggled to recruit and staff were dissatisfied with its teaching structure. This consisted of short modules, which did not allow enough time for subject depth, and which out of necessity loaded all the assessments at the end of the modules.

The MA was therefore re-launched in 2013 and was comprehensively redesigned along blended learning lines. There were various reasons for this choice of delivery mode. Firstly, the course team hoped that the blended structure would make the course attractive to students. The evening and distance elements should appeal to part-time learners: blended learning has acknowledged benefits for non-traditional learners with work and family responsibilities, who require flexibility and considerate scheduling (Gulc, 2006, p.18). Additionally, the new structure can simultaneously work as a full-time programme, and has been running on both bases from October 2014. As well as aiding recruitment, the course team hoped that the new structure would bring pedagogical benefits, allowing more opportunities for reflection, subject depth and skills development, and incorporating a more continuous and formative assessment pattern.

The seven-week 20-credit modules were therefore replaced with fourteen-week 30-credit modules, the delivery of which would be divided 50/50 between evening classes and online learning. Although the class contact time per credit therefore decreased, the overall amount of contact time increased. A new menu of 30-credit modules was validated to support this new mode: as Campbell and Kimball argue, "'grafting” new technologies onto old course design rarely works. The best time to implement a blended learning approach is when courses are undergoing significant changes' (2010, p.88).

As with any new programme, the course team were keen to evaluate its pilot year. The programme leader therefore designed this research project in order to explore the pedagogical implications of this structural change. The year-long project was facilitated by funding from the Institute of Learning and Teaching at the University, where innovative online and blended provision for students at all levels' is an institutional priority (Institute for Learning and Teaching, 2014).

As it was the pilot year of the re-launched course, and because it was made available late in the year, it was taken by five students - a smaller-than-usual cohort. As the first year of a two-year part-time course, the students took two 30-credit modules: 'Men of Arms: Masculinity and War in Britain, 1760-1918' in the autumn, and 'Exploring Early Modern Society' in the spring. These two modules adopted the same structure, alternating between evening classes and online activities over 14 weeks. They both had a fortnightly topic structure, where the classes came first and the online week was used for follow-up activities, but the course structure also allows tutors to reverse this pattern. The evening classes were conventional face-to-face sessions lasting 3 hours, for which students would prepare by engaging with suggested readings provided online or via a reading list. As is usual for the teaching of History at this level, there is no 'lecturing' by 
the tutor, and the time is instead used flexibly for roundtable discussions and work on documents.

The online week had two main elements. An online seminar was conducted via a discussion board throughout the week, usually on the same topic area as the preceding 'class' week, in order to deepen students' engagement with it. The range of tasks included the following:

- $\quad$ Tutor would set reading and would suggest questions to start a discussion

- $\quad$ Tutor would share some of their own work in progress and invite comments

- $\quad$ Discussion of a feature film or YouTube video clip

- Set a loosely-defined research task on an online repository, in the topic area of the previous class

The students would have all week to post responses to this, to each other and to follow-up questions from the tutor. Parallel to this, the students would do part of their assessment online. The two modules had a common assessment pattern, consisting of a blog (reflecting on primary sources posted fortnightly by the tutor) and a 5000-word essay (due at the conclusion of the module). As such, this study's findings relate to the overall blended learning structure rather than particular modules - although, as we will see, the students did note that the two different tutors had different 'online styles'.

\section{Methods}

This study sought to evaluate the delivery mode of the MA History, focusing on the student experience of blended learning and its implications for the development of 'History' postgraduate skills. Because the project was about the student experience, it employed a student researcher to contribute to the project design, to gather the data from the students and to coproduce project outputs, including a conference paper and this article. The employment of a student researcher was informed by Northampton's well established URB@N scheme (Undergraduate Research Bursaries at Northampton), whereby undergraduate students work as paid assistants on pedagogical research projects. As well as providing a valuable experience for the student researcher and enhancing partnerships between students and staff, this approach has the added benefit of providing better data, since a student researcher is more likely to get candid responses from their peers than a member of academic staff would (Butcher \& Maunder, 2014). All students consented to their participation in the study. All the students were part time; three were female and two male; three were recent graduates and two were returning to study after a longer break. Data was gathered by means of an online survey at the end of semester one and a face-to-face focus group at the end of semester two. Mirroring the ethos of the blended MA itself, it was valuable to give students two different fora in which to express their views: the survey allowed individual and considered responses, whereas the focus group was more conversational and immediate.

The online survey (OS) went live at the end of the first module and three students completed it. Although a survey could have gathered quantitative data, given the size of the cohort the emphasis was on qualitative data: this data was sufficiently rich to justify a detailed study of a 
small sample. The student researcher designed the questions. Question 3 was multiple choice, whereas the others were free text fields:

1) Do you like the blend of classes and with online learning, and why is this?

2) Do you feel that the fortnightly pattern worked as a 'blend', and why?

3) Which of the following activities did you like best?

- $\quad$ Read a text and discuss it

- Discuss work in progress by lecturer

- $\quad$ Discuss a feature film

- $\quad$ Research task on an online repository

4) Why was this?

5) Are there any advantages to an online seminar over conventional class discussion?

6) Are there any disadvantages?

7) Did you encounter any problems, technical or otherwise, with the online elements of the course?

8) Do you have any further comments about the blend of 'online' and 'face to face' learning?

The focus group (FG) took place at the end of the second module and four students attended. It was facilitated by the student researcher (no tutors were present). This had a looser agenda since we wanted the students themselves to drive the discussion. The key discussion points were: whether they were enjoying the course, whether they thought the blend of class and online was beneficial, its impact on skills development, their experience of using a discussion board, and technical issues with the VLE. The discussion was recorded and transcribed, and the responses were anonymised and coded.

\section{Results}

From the data collected it was clear that the students valued the convenience of the format. As one stated: 'Personally it fits in with my lifestyle and the fact that I live at a distance from the university. I also find that it paces the learning at a level I enjoy' (OS 1). In both the survey and the focus group, the students also reflected at length on the pedagogical implications of blended learning, and these reflections clustered around three main themes.

\section{Class versus online}

The students acknowledged the advantages and disadvantages of both the online and class elements of the course. One student in the survey reported: 'I feel that I get more from the face to face sessions as we cover more, although the online sessions give one much more time to think about a question and to reflect on the topic and reading' (OS 2). They said that the online elements of the course presented them with 'more time to think and reflect' as the process of planning a response naturally led to a more carefully thought out and developed answer as opposed to a quick response in the classroom: 'Because you are typing your response you have to think more carefully about what you are saying and perhaps give a more considered response' (OS 2). 
On the other hand, disadvantages of the online format included 'lack of face to face interaction' (OS 1) and the slowness and disjointedness of some online discussions:

'Someone answers something at nine o'clock in the morning, then someone answers at five in the afternoon, the conversation has moved on' (FG 2).

'It was a bit disjointed wasn't it? It doesn't flow' (FG 3).

One respondent felt more anxious about their online contributions because written responses would be more permanent and would be analysed more than a response in class, 'where there is a more conversational feel' (OS 2).

\section{Task preferences}

Question 3 in the online survey asked students which online task they had most enjoyed: they unanimously preferred the research task, as they found it 'interesting and informative' (OS 1). Even before the focus group, it was clear that this was the most popular activity from the level of participation on the discussion board that week: there were a total of 27 posts, compared to 15 posts the previous week, where the task was to discuss an article on methodology. The posts for the research task were also longer and more sophisticated, developing themes from the previous class and taking them in new directions. They consistently displayed features that we would expect to see in postgraduate-level work: linking primary sources to secondary debates, reflections on genre and authorial intention, and thinking about the nature of political controversy in a specific historical context. In general, the level of participation in the online seminar varied week by week: student participation did tail off, possibly because towards the end of the module they were concentrating on the assessed essay, which other studies have also found (Navickas, 2010). As the primary source research task was the most popular and effective activity, the tutor of the second module adopted it for all the online seminars in the second semester.

\section{Online etiquette}

Some of the students did not feel that the structure of the programme was fully explained to them at the outset, therefore they were not entirely sure what to expect from the blended delivery pattern (FG 1). One aspect of this was a degree of uncertainty about the etiquette of using a discussion board. All forms of communication have an etiquette, and just as the seminar format can be unfamiliar to new undergraduates, a discussion board can be unfamiliar to those who have never used one before - or it can operate in a different way in an HE setting than it might in more familiar ones like a chat room or Facebook (FG 4). The intention was for students to respond to each other as well as the tutor, in the way that a free-form discussion would progress in a seminar. However, students were unsure of whether they were meant to reply to their colleagues or the tutor, and therefore tended to respond to the tutor in their own thread. They explained that they felt that there was 'a barrier to placing comments on other students' ideas' (FG 3): 
'I think as well that when we are chatting [in class] I could say, oh and this, but online I still can't get over the idea that I could comment on someone else's thread. You just don't feel comfortable adding a thought to somebody's thought online. Whereas talking is natural, just a conversation' (FG 4).

This perhaps explains why, of the 55 student posts on the 'Men of Arms' discussion board, only $12(22 \%)$ were a direct reply to another student: students prefer to reply directly to the tutor rather than continue a discussion in another student's thread. As with a face-to-face seminar, however much the tutor may want to have a 'roundtable', there is still a hierarchy at play: ironically, the conventions of the discussion board may serve to exacerbate rather than mitigate this.

This relates to the students' other key point, that the two tutors had different online styles, which impacted on the nature of the interactions taking place on the discussion boards. One would reply directly to students, making the discussion a very individual Q\&A between tutor and student: 'it was much more this is what it is, you answer to me and I will get back to you'. Whereas the other would try to open out the discussion and invite the other students to take it in different directions: 'he would build it and build it' (FG 3). The tutor's online etiquette, as well as that of the students, therefore has a big impact on the learning experience.

\section{Discussion}

These results suggest that students perceive important differences between online and classroom learning, and that each has its advantages and disadvantages. In the light of this, it is possible to reflect upon the extent to which the adoption of this blended learning structure impacted upon the attainment of 'History' skills. With reference to the History benchmark's seven 'skills and qualities of mind' (QAA, 2008a, p.4-5), it is suggested that the online element may offer some significant enhancements over programmes that are primarily classroom-based.

As the students noted above, asynchronous communication allows greater time for reflection and understanding (skills 1 and 3), for the writing of considered responses (skill 7) and for the analysis of sources and historiography (skills 2, 4 and 5). The provision to set up 'research' tasks underline intellectual independence and problem solving (skill 6). The online part of the programme therefore involves all of these skills, to a greater or lesser extent, but the evidence from the students suggests that it was not without its problems. Disadvantages included the slowness of online discussions, perceived barriers to debating with other students, and uncertainty about online conduct.

The 'class' element of the blend involves the same skill set, but with significantly different emphases. A discussion in class clearly involves marshalling an argument in an oral rather than a written form (skill 7), but it is also happening more spontaneously. Some students preferred its 'more conversational feel' (OS 2), and felt more comfortable disagreeing with other students in the context of a conversational interaction. An understanding of diverse and complex situations (skills 1 and 3) may therefore emerge through dialogue rather than through protracted individual reflection. A source analysis in class (skills 2, 4 and 5) may not give students time to go away 
and carry out background research, but will encourage them to make unexpected links with their prior knowledge and understanding.

This therefore underlines the value of combining online and class elements, rather than pursuing one in isolation, and of developing a blend of the two that works in practice. In general, the online activities on the MA tended to be very focused in nature - concentrating on a particular text, interpretation or episode - whereas the classes could be much more broad-ranging. Most postgraduate History programmes would need to do both - to develop syntheses and an understanding of the bigger picture on the one hand; and to drill down on the specifics of methodologies and source materials on the other - so this blend of delivery modes serves our pedagogical requirements well.

This study has therefore helped us to understand the ways in which blended learning can enhance skills development, and also how our chosen blend can be finessed in order to optimise this. The 'flow' of activities within a module adopting this blended structure can be expressed as a diagram (Figure 1). Based upon the results of the student feedback, the seven 'E's in the diagram emphasise what the tutor can be doing at the various points of the course to make the most of the possibilities of this particular blend. As a model, this framework is clearly transferable to other postgraduate History programmes, but as the structure itself is mostly generic it could doubtless be applied to other disciplines and levels of study as well.

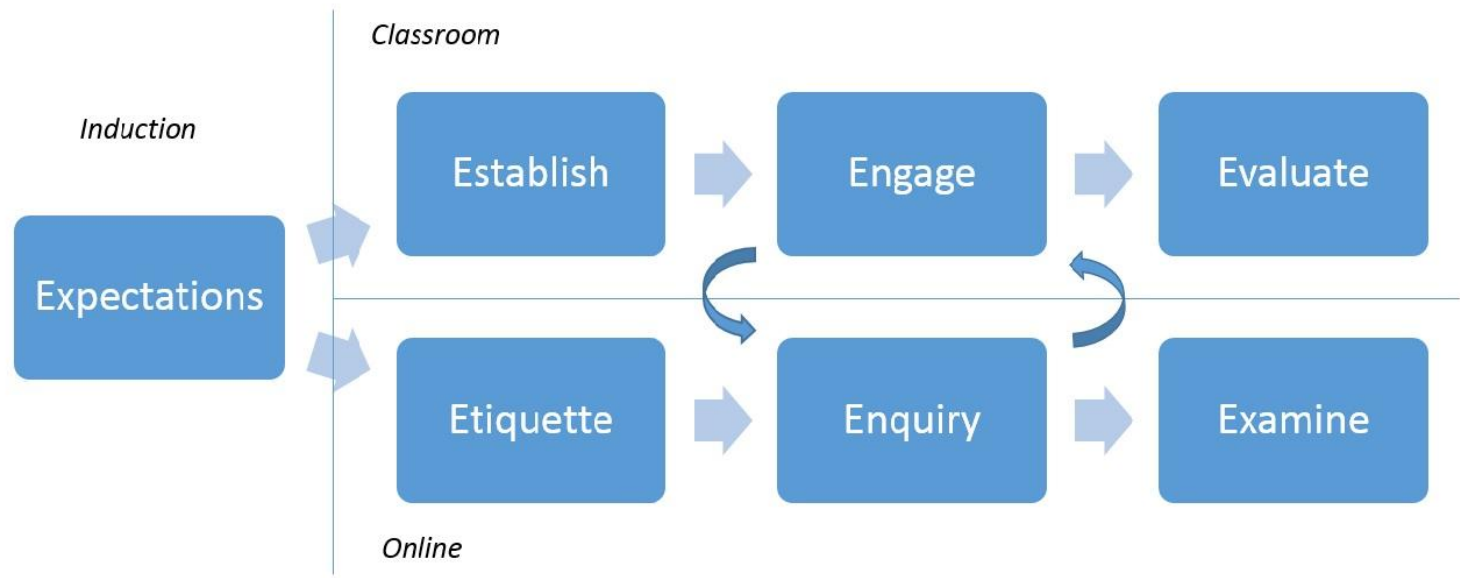

Figure 1: Flow of activities in a blended module

The diagram begins before the learning activities themselves, at the point of course induction. The survey and the focus group both underlined the importance of student expectation. Students who are accustomed to a classroom experience (as will most people who have done a UK undergraduate degree) may be unclear about what they are getting. One student who had deferred entry after applying for the previous version of the programme felt that it was 'too much of a distance learning programme' (OS 3). It is therefore beneficial for students to go into a blended programme with a good understanding of how it is going to run, and how the various elements relate to one another. 
Induction is also essential at the level of the module itself. It is important to establish the rhythm of the different activities and, for the online element in particular, to make sure that the etiquette for participation is clear (Dawson et al., 2007, p.2). For an online seminar, this may include the timing and frequency of posts, the acceptability of engaging with other students, and the type of language that is encouraged (formal/informal, referenced/unreferenced, short/detailed, supportive/critical, and so on).

Once the module gets into the fortnightly cycle of class and online activities, it is important to recognise the qualitatively different nature of these experiences, and to tailor the learning appropriately (Garrison \& Kanuka, 2004, p.97). Classes can be used to engage learners in the material, to debate with tutors and peers in the moment, to create links and syntheses, and to help students to locate their prepared work in the context of a larger field. The asynchronous nature of the online element lends itself to enquiry, incorporating research tasks, learner independence, reflection and mastery of detail. As we have seen, students expressed a strong preference for independent research tasks for the 'online' week.

The model can help us to understand the outputs of this experience. As Holden and Poole (2010, p.14) argue, it is beneficial if some aspect of the online learning is examined. In the case of these modules, we did not assess the online seminar itself, which would be akin to a 'participation grade' in a classroom course: we did not feel that postgraduates should be rewarded with degree credit just for turning up. But running a form of continuous assessment alongside the online seminars - in this case, a blog about primary sources - has the advantages of making the assessment formative, spreading the assessment workload throughout the semester, and ensuring that students regularly engage with the online element. Finally, evaluate the module, and aim to incorporate any lessons learned about the blend into future module design.

\section{Conclusion}

Overall, we feel that the blended structure of the MA History at Northampton has been successful. Crucially, the overall impression of the delivery mode from the students themselves was a positive one, and their critical feedback can help us to develop the course further in a positive way. Issues requiring further attention included student expectation, the setting of tasks that make the most of the online format, and the etiquette of students and staff alike when using discussion boards. We do feel, however, that these can be addressed in a positive way within the new course structure. In general, this study has found that both online and classroom learning can address the key skills associated with postgraduate study within a discipline like History. But since they do so in different ways, and since the drawbacks of one can be mitigated by the other, combining them in an appropriate blend can offer a significant pedagogical enhancement.

\section{References}

Butcher, J. and Maunder, R. (2014) 'Going URB@ N: exploring the impact of undergraduate students as pedagogic researchers'. Innovations in Education and Teaching International, 51 (2): 142-152. http://dx.doi.org/10.1080/14703297.2013.771967 
Campbell, V. J. and Kimball, R. A. (2010) 'The blended history classroom: keeping the student central'. Teaching History: A Journal of Methods, 35 (2): 79-91.

Dale, C. (2006) 'Using technologies for blended learning'. Link 17: 11-12.

Dawson, J., Murray, K., Parvis, S. and Paterson, J. (2007). Using weblogs to encourage reflective learning in History and Classics. Higher Education Academy.

Garrison, D. R. and Kanuka, H. (2004) 'Blended learning: uncovering its transformative potential in Higher Education'. The Internet and Higher Education, 7 (2): 95-105. http://dx.doi.org/10.1016/j.iheduc.2004.02.001

Gulc, E. (2006) 'Using blended learning to accommodate different learning styles'. Link, 17: 1720.

Holden, K. and Poole, S. (2010) Exploring staff and student engagement with discussion boards in the postgraduate History curriculum at UWE. https://www.heacademy.ac.uk/resource/exploring-staff-and-student-engagement-discussionboards-post-graduate-history-programme (accessed 19/8/15).

Institute for Learning and Teaching (2014) homepage http://www.northamptonilt.com (accessed 10 October 2014).

McGee, P. and Reis, A. (2012) 'Blended course design: a synthesis of best practices'. Journal of Asynchronous Learning Networks 16 (4): 7-22.

McConnell, D. (2005) 'Examining the dynamics of networked e-learning groups and communities'. Studies in Higher Education 30(1): 25-42.

http://dx.doi.org/10.1080/0307507052000307777

Navickas, K. (2010) Case study: using a VLE discussion board with final-year history undergraduates.

http://www2.warwick.ac.uk/fac/cross_fac/heahistory/elibrary/internal/cs_navickas_vle_xxxxxxx $\underline{\mathrm{x} /}(\operatorname{accessed} 19 / 8 / 15)$

Osguthorpe, R. and Graham, C. (2003) 'Blended learning environments: definitions and directions'. Quarterly Review of Distance Education 4 (3): 227-33.

Quality Assurance Agency (2008a) History. Gloucester: Quality Assurance Agency.

Quality Assurance Agency (2008b) The Framework for Higher Education Qualifications in England, Wales and Northern Ireland. Gloucester: Quality Assurance Agency.

Sharpe, R., Benfield, G., Roberts, G. and Francis, R. (2006) The undergraduate experience of blended e-learning: a review of UK literature and practice. The Higher Education Academy. 
https://www.heacademy.ac.uk/resources/detail/teachingandresearch/Undergraduate_Experience (accessed 19/8/15)

Smyth, S., Houghton, C., Cooney, A. and Casey, D. (2012) 'Students' experience of blended learning across a range of postgraduate programmes'. Nurse Education Today 32 (4): 464-68. http://dx.doi.org/10.1016/j.nedt.2011.05.014

Timmins, G. (2004) 'History around you': online seminars and discussions https://histsotleurope.wordpress.com/geoff-timmins-history-around-you-on-line-seminars-anddiscussions (accessed 19/8/15).

Whitelaw, P. A. (2006) 'Getting them ready for lecturers: a personal perspective'. Link 17: 2223.

\section{About the author}

Matthew McCormack is Associate Professor of History at the University of Northampton Email: matthew.mccormack@ northampton.ac.uk

Natalie Hanley-Smith is a graduate of the University of Northampton, where she is currently studying for MA History 